\title{
Ceramide: a Key Signaling Molecule in a Guinea Pig Model of Allergic Asthmatic Response and Airway Inflammation
}

\author{
Emanuela Masini, Lucia Giannini, Silvia Nistri, Lorenzo Cinci, Rosanna Mastroianni, \\ Wei Xu, Suzy A. A. Comhair, Dechun Li, Salvatore Cuzzocrea, George M. Matuschak, \\ and Daniela Salvemini
}

Department of Preclinical and Clinical Pharmacology (E.M., L.G., R.M.) and Anatomy, Histology and Forensic Medicine, Section of Histology (S.N., L.C.), University of Florence, Florence, Italy; Pathobiology, and Pulmonary, Critical Care Medicine, Cleveland Clinic, Cleveland, Ohio (W.X., S.A.A.C.); Internal Medicine, Division of Pulmonary, Critical Care and Sleep Medicine, and Department of Pharmacological and Physiological Sciences, St. Louis University School of Medicine, St. Louis, Missouri (D.L., G.M.M., D.S.); and Clinical and Experimental Medicine and Pharmacology, School of Medicine, University of Messina, Italy and Centro Neurolesi "Bonino-Pulejo", Messina, Italy (S.C.)

Received September 12, 2007; accepted November 26, 2007

\begin{abstract}
Although mechanisms involved in the pathogenesis of asthma remain unclear, roles for oxidative/nitrosative stress, epithelial cell apoptosis, and airway inflammation have been documented. Ceramide is a sphingolipid with potent proinflammatory and proapoptotic properties. This study aimed at determining whether increased formation of ceramide contributes to the development of airway inflammation and hyper-responsiveness, using a well characterized in vivo model of allergic asthmatic response and airway inflammation in ovalbumin-sensitized guinea pigs. Aerosol administration of ovalbumin increased ceramide levels and ceramide synthase activity in the airway epithelium associated with respiratory abnormalities, such as cough, dyspnea, and severe bronchoconstriction. These abnormalities correlated with nitrotyrosine formation in the airway epithelium and oxidative/nitrosative stress,
\end{abstract}

epithelial cell apoptosis, and airway inflammation evident by the infiltration of neutrophils and eosinophils in lung tissues, mast cell degranulation, and release of prostaglandin $D_{2}$ and proinflammatory cytokines. Inhibition of de novo ceramide synthesis with the competitive and reversible inhibitor of ceramide synthase fumoni$\sin B 1(0.25,0.5$ and $1 \mathrm{mg} / \mathrm{kg}$ b.wt.), given i.p. daily for 4 days before allergen challenge, attenuated nitrotyrosine formation and oxidative/nitrosative stress, epithelial cell apoptosis, and airway inflammation while improving the respiratory and histopathological abnormalities. These results implicate ceramide in the development of allergic asthmatic response and airway inflammation. Strategies aimed at reducing the levels of ceramide and downstream events should yield promising novel anti-asthmatic agents.
Asthma is defined by airway inflammation and remodeling and bronchial hyper-responsiveness (Busse and Lemanske, 2001). The role of inflammation in asthma is well established, and neutrophils, eosinophils, and mast cells within the lung have been shown to have pivotal roles for the initiation and maintenance of airway inflammation (Andreadis et al., 2003; Barnes, 2004). Besides the classical allergen-dependent pathways, reactive oxygen and nitrogen species produced during airway inflammation activate

This work was supported by St. Louis University Seed Funds PPG PO1 081064 and by funds from the University of Florence (Florence, Italy).

Article, publication date, and citation information can be found at http://jpet.aspetjournals.org.

doi:10.1124/jpet.107.131565 these cells to release histamine, prostaglandins, leukotrienes, proteases, and cytokines, which exacerbate the response and directly participate to the pathogenesis of asthma (Andreadis et al., 2003; Comhair et al., 2005). In experimental models, reactive oxidant species reproduce multiple pathophysiologic asthmatic hallmarks: bronchoconstriction, $\beta$-adrenergic dysfunction, cytokine production, mucus hypersecretion, microvascular leak and edema, epithelial damage and sloughing, airway remodeling, and hyper-responsiveness (Andreadis et al., 2003; Comhair et al., 2005). In support of these data, bronchial obstruction in human asthma is associated with an increased spontaneous and stimulus-induced production of oxygen free radicals by inflammatory cells in airway lumen (Calhoun et al., 1992).

ABBREVIATIONS: S1P, sphingosine 1-phosphate; TNF, tumor necrosis factor; OVA, ovalbumin; NBT, nitro blue tetrazolium; FB1, fumonisin B1; PBS, phosphate-buffered saline; SOD, superoxide dismutase; DTT, dithiothreitol; MBP, major basic protein; PAO, pressure at the airway opening; Ac-DEVD-AMC, Ac-Asp-Glu-Val-Asp-AMC; 8-OHdG, 8-hydroxy-2'-deoxyguanosine; IL, interleukin; PARP, poly(ADP-ribose)polymerase; S1Pr, sphingosine 1-phosphate receptor; TdT, terminal deoxynucleotidyl transferase; TUNEL, TdT-mediated dUTP nick-end labeling; PGD ${ }_{2}$, prostaglandin $\mathrm{D}_{2}$. 
Ceramide is a sphingolipid with powerful proapoptotic and proinflammatory properties and has been implicated in oxidative/nitrosative stress (Huwiler et al., 2000; Pettus et al., 2002; Kolesnick and Fuks, 2003). Ceramide is generated by enzymatic hydrolysis of sphingomyelin by sphingomyelinases, the so-called sphingomyelin pathway. Alternatively, de novo ceramide can be synthesized by serine palmitosyltransferase and ceramide synthase, and it is stimulated by numerous chemotherapeutics and cytokines, which cause a sustained elevation of ceramide levels (Huwiler et al., 2000; Kolesnick, 2002). Steady-state availability of ceramide is regulated by ceramidases that convert ceramide to sphingosine by catalyzing the hydrolysis of its amide group (Huwiler et al., 2000; Kolesnick, 2002). The importance of ceramide activation to inflammation derives from activation of protein kinases and phosphatases in diverse downstream pathways (Huwiler et al., 2000) and from its generation of additional second messengers such as sphingosine 1-phosphate (S1P) (Le Stunff et al., 2004). Thus, S1P generated upon phosphorylation of sphingosine by sphingosine kinase is the natural ligand for a family of $\mathrm{G}$ protein-coupled receptors originally termed endothelial differentiation genes and recently renamed S1P receptors (S1Pr). Five distinct SIPrs have been identified, although selective receptor antagonists have not been reported (Chun et al., 2002). These receptors couple to different $G$ proteins and elicit a wide array of cellular responses relevant to airway inflammation (Spiegel and Milstien, 2003). An involvement of S1P in asthma has been recently reported in animal models (Roviezzo et al., 2007) and humans (Roviezzo et al., 2004). Considering the importance of epithelial apoptosis in asthma, ceramide is well established as a major proapoptotic mediator following radiation, chemotherapeutics, or exposure to proinflammatory cytokines, including TNF- $\alpha$, IL- $1 \beta$, IL-6, and oxidative/nitrosative stressors (Huwiler et al., 2000; Kolesnick, 2002; Pettus et al., 2002). Proapoptotic effects of ceramide involve multiple mechanisms, such as activation of the kinase suppressor of Ras (Zhang et al., 2002), stimulation of protein phosphatases 1 and $2 \mathrm{a}$ (Chalfant et al., 2002), increased cathepsin D activity (Heinrich et al., 2000), and direct alteration of plasma and mitochondrial membrane signaling properties by oxidative/ nitrosative stress (Siskind et al., 2002; Petrache et al., 2005).

In further support of ceramide as a proinflammatory mediator, reduced inflammatory responses have been described through pharmacological manipulation of ceramide synthesis, inhibition of the sphingomyelinase or de novo pathways, and attenuated synthesis of TNF- $\alpha$, IL- $1 \beta$, and IL- 6 as well as reactive oxygen species (Won et al., 2004). Furthermore, ceramide has been reported to promote oxidative stress and enhance expression of endothelial and inducible nitric-oxide synthases (Won et al., 2004) and cyclooxygenase-2 (Newton et al., 2000). Furthermore, ceramide-induced activation of the transcription factor $\mathrm{NF}-\kappa \mathrm{B}$ and p38 kinase amplify the production of several inflammatory mediators and adhesion molecules (Won et al., 2004). Therefore, it is not surprising that both preclinical and clinical studies support a causal role for ceramide in other conditions characterized by inflammation, oxidative/nitrosative stress, and apoptosis, such as radiation-induced injury (Kolesnick and Fuks, 2003), sepsis (Delogu et al., 1999), acute lung injury (Goggel et al., 2004), and emphysema (Petrache et al., 2005).

Collectively, these findings led us to hypothesize the par- ticipation of ceramide as a novel signaling lipid in asthma. Using a well characterized guinea pig model of allergic asthma-like reaction (Suzuki et al., 2004; Masini et al., 2005), our findings show that increased levels of ceramide contribute to functional, biochemical, and histological changes associated with allergic airway inflammation and dysfunction and consequently support a role of this lipid mediator in asthma.

\section{Materials and Methods}

\section{Animals}

Male Hartley albino guinea pigs were used. They were purchased from a commercial dealer (Rodentia, Bergamo, Italy) and quarantined for 7 days at 22 to $24^{\circ} \mathrm{C}$ with a 12-h light/12-h dark cycle before use. The experimental protocol was designed in compliance with the recommendations of the European Economic Community (86/609/ CEE) for the care and use of laboratory animals and in agreement with the Good Laboratory Practice. It was approved by the animal care committee of the University of Florence (Florence, Italy) where all of the in vivo experiments were carried out. At the end of the treatment, the animals weighed 350 to $400 \mathrm{~g}$.

\section{Animal Sensitization and Treatments}

The guinea pigs were divided into six experimental groups with $n=10$ animals per group.

Group 1. Animals were injected with isotonic saline $(5 \mathrm{ml} / \mathrm{kg}$ b.wt., i.p., plus $5 \mathrm{ml} / \mathrm{kg}$ b.wt. s.c.) and 18 days later received an aerosol of ovalbumin (OVA; Fluka, Buchs, Switzerland) dissolved in saline $(5 \mathrm{mg} / \mathrm{ml})$ and used as negative controls. They are referred to as naive OVA-challenged animals.

The remaining guinea pigs were sensitized with $100 \mathrm{mg} / \mathrm{kg}$ b.wt. i.p. plus $100 \mathrm{mg} / \mathrm{kg}$ b.wt. s.c. OVA dissolved in saline $(20 \mathrm{mg} / \mathrm{ml})$. After 18 days, they were challenged with an OVA aerosol $(5 \mathrm{mg} / \mathrm{ml}$ saline) to verify sensitization by evaluation of allergen-elicited respiratory changes, as described below. The animals were withdrawn from antigen exposure at the first signs of respiratory abnormalities. The guinea pigs reactive to the inhaled antigen were used for the further experiments. By this protocol, only three of 50 animals failed to develop sensitization. Three days later, the sensitized guinea pigs were divided in the following groups.

Group 2. Animals were treated with a subcutaneous injection ( 0.5 $\mathrm{ml}$ ) of PBS for 4 days before undergoing the provocation test with an aerosol of saline alone. These are referred to as the sensitized, unchallenged group.

Group 3. Animals were treated with a subcutaneous injection $(0.5$ $\mathrm{ml}$ ) of PBS for 4 days before undergoing the provocation test with aerosolized OVA ( $5 \mathrm{mg} / \mathrm{ml}$ saline). These are referred to as the sensitized OVA-challenged group.

Groups 4 to 6. Animals were treated with a subcutaneous injection $(0.5 \mathrm{ml})$ of fumonisin B1 (FB1; Sigma-Aldrich, Milan, Italy), a competitive and reversible inhibitor of ceramide synthase, dissolved in PBS as vehicle, and tested over three daily doses $(0.25,0.5$, and 1 $\mathrm{mg} / \mathrm{kg}$ b.wt.) for 4 days before undergoing the provocation test with aerosolized OVA. These are referred to as the sensitized, FB1treated OVA-challenged group.

\section{Challenge with Inhaled OVA and Evaluation of Respiratory Activity}

Five guinea pigs from all groups were individually placed in an airtight transparent whole-body plethysmographic chamber, as described previously (Suzuki et al., 2004; Masini et al., 2005). The changes in inner pressure in the respiratory chamber induced by breathing were monitored with a high-sensitivity pressure transducer (Battaglia-Rangoni, Bologna, Italy) connected to a PC2400A channel polygraph (Battaglia-Rangoni). Upon breath stabilization, usually occurring within 30 to $60 \mathrm{~s}$, guinea pigs were challenged with 
OVA aerosol for $10 \mathrm{~s}$. Animals from the naive group were included in the aerosol challenge to reveal possible breath alterations due to nonspecific stimulation of the airways by the aerosol droplets. The respiratory activity of the animals subjected to the different treatments was monitored for $10 \mathrm{~min}$ after the onset of aerosol administration and classified according to the criteria reported previously (Masini et al., 2005). In particular, cough was assumed as a transient change in the pressure (a rapid inspiration followed by a rapid expiration), whereas dyspnea was assumed as a series of irregular breaths of abnormally elevated frequency (tachypnea) and amplitude or as repeated gasping. Movements of the guinea pigs were visually monitored by two trained observers who were blinded to group assignment of the animals. In this way, any motion- and sneezingrelated changes in the inner pressure of the body chamber could also be disregarded. The following parameters were evaluated: i) latency time for the first cough stroke (seconds); ii) cough severity, the product of cough frequency (cough strokes per minute), and mean cough amplitude (excess pressure over the normal breath); and iii) latency time for the onset of dyspnea (seconds).

\section{Measurement of Airway Bronchoconstriction}

Anesthetized guinea pigs from each group $(n=5)$ above were mechanically ventilated by a constant volume method as reported previously (Masini et al., 2005). Animals were injected with 100 $\mathrm{mg} / \mathrm{kg}$ b.wt. sodium pentothal (Abbott, Latina, Italy) to induce anesthesia and abolish natural respiration. Body temperature was monitored continuously and maintained constant at $37^{\circ} \mathrm{C}$. The trachea was cannulated with a polyethylene tube (inner diameter, $2 \mathrm{~mm}$ ), and the animals were ventilated with a small-animal respirator (Harvard, Edenbridge, UK), adjusted to deliver a tidal volume of 10 $\mathrm{ml} / \mathrm{kg}$ at a rate of $60 \mathrm{strokes} / \mathrm{min}$. Changes in lung resistance to inflation (pressure at the airway opening; PAO), specifically the lateral pressure of the inlet air tube, were registered by a pressure transducer connected to a polygraph (Battaglia-Rangoni). After 10min stabilization, the basal inflation pressure was measured. Each animal was then exposed to an OVA aerosol for $1 \mathrm{~min}$ through the tracheal inlet air pipe. Changes in inflation pressure, which are directly related to airway resistance, were recorded for $10 \mathrm{~min}$ after the beginning of OVA aerosol and expressed as percentage changes over the basal values. These animals were also used for collection of bronchoalveolar lavage fluid, as detailed below.

\section{Post-Mortem Analyses}

At the end of the breath recording period, the animals were removed from the plethysmographic chamber, and they were killed by decapitation $50 \mathrm{~min}$ later (i.e., $1 \mathrm{~h}$ after aerosol administration). The gross appearance of the lungs, liver, and kidneys was examined. No macroscopic alterations of these organs that could be related to a toxic effect of FB1 treatment were observed. Lung tissue samples from each animal from the middle and the lower lobes were taken for biochemical and morphological analyses, as described below. Before opening the thorax, in some animals, bronchoalveolar lavage fluids were obtained by insertion of a cannula into the trachea and instillation of $3 \mathrm{ml}$ of PBS, $\mathrm{pH}$ 7.4. In the animals used for measurement of airway bronchoconstriction, bronchoalveolar fluid was collected after three flushes into the bronchial tree and centrifuged at $1100 \mathrm{~g}$ for $30 \mathrm{~min}$. The cell-free supernatant was collected, and its volume was measured and frozen at $-70^{\circ} \mathrm{C}$ until needed.

\section{Histologic and Morphometric Analyses}

Lung tissue samples, two from each animal, were fixed by immersion in Mota fluid (50\% ethanol in water, $0.5 \%$ acetic acid, and $15 \%$ basic lead acetate) and embedded in paraffin. This fixative solution allows a rapid infiltration of the tissue, with only minimal artifactual shrinking, thus providing a tissue morphology, which is representative of the lung features in vivo. Lung tissue sections, $5 \mu \mathrm{m}$ thick, were used for morphometric analysis, as reported previously (Masini et al., 2005).

A first series of determinations was carried out on hematoxylin and eosin-stained sections to evaluate the surface area of alveolar air spaces. In each guinea pig, determinations were performed on tissue sections cut from the two different lung samples, examined with a $10 \times$ objective. Four randomly chosen microscopic fields per animal (two fields per section) were analyzed. At the chosen magnification, each field corresponds to a tissue area of $570,224 \mu \mathrm{m}^{2}$ that includes an average of 300 alveolar profiles. The same tissue sections were used to evaluate the surface area of bronchial lumina selected by: i) histological appearance of small-sized muscular bronchi; and ii) transverse or slightly oblique cross-section. In each guinea pig, measurements were carried out on four to six randomly chosen bronchi from the tissue sections cut from the two different lung samples examined with a $20 \times$ objective. Digital images of the microscopic fields to be analyzed were recorded, and surface area measurements were carried out using the Scion Image Beta 4.0.2 image analysis program (Scion Corp., Frederick, MD) upon the appropriate threshold to include only blank tissue-free air spaces. The mean values $( \pm$ S.E.M.) of alveolar and bronchial luminal areas were then calculated for each experimental group.

A second series of determinations was carried out on sections stained with Astra blue (Fluka, Buchs, Switzerland) to evaluate the optical density of lung-mast cells, which is related to the content of secretory granules. In each guinea pig, determinations were performed on tissue sections cut from the two different lung samples, according to the method described previously for similar purposes (Masini et al., 2005). The mast cells were viewed by the same image analysis device described above, using a $100 \times$ oil immersion objective. Measurements of optical density were carried out on selected mast cell profiles using the previously reported program. In each animal, 30 different mast cells, 15 from each lung sample, were analyzed, and the mean optical density value ( \pm S.E.M.) was then calculated for the entire experimental group.

A third series of determinations was carried out on sections immunostained with anti-major basic protein (MBP), a marker for eosinophils. Sections were treated with $0.1 \%$ trypsin for $10 \mathrm{~min}$ to retrieve antigen and then with $0.3 \% \mathrm{H}_{2} \mathrm{O}_{2}(\mathrm{v} / \mathrm{v})$ in $60 \%$ methanol (v/v) to quench endogenous peroxidase and finally incubated overnight with mouse monoclonal anti-human eosinophil MBP antibodies (clone BMK13; Chemicon, Temecula, CA; 1:50 in PBS). Immune reaction was revealed by the indirect immunoperoxidase method (Vectastain Elite kit; Vector Laboratories, Burlingame, CA), using $3,3^{\prime}$-diaminobenzidine as chromogen. As negative controls, sections incubated with only the primary or the secondary antisera were used. In each guinea pig, the number of MBP-positive eosinophils was counted in 10 randomly chosen microscopic fields at a $200 \times$ final magnification (test area: 72,346 $\mathrm{mm}^{2}$ ). Values obtained from two different observers were averaged.

\section{Immunohistochemical Analysis of Ceramide and Nitrotyrosine}

Lung tissues were fixed in paraformaldehyde ( $4 \% \mathrm{wt} / \mathrm{vol})$ in $0.1 \mathrm{M}$ PBS, $\mathrm{pH} 7.4$, for $2 \mathrm{~h}$ and processed to paraffin sections. After deparaffinization, the slides were treated in $2 \%$ citric acid buffer, $\mathrm{pH} 6.8$, for $5 \mathrm{~min}$ in microwave oven to retrieve antigens, blocked in $10 \%$ goat serum in PBS, and incubated with monoclonal anti-ceramide (1:50; Sigma-Aldrich) or anti-nitrotyrosine antibodies (1:100; Upstate Biotechnology, Lake Placid, NY) at $4^{\circ} \mathrm{C}$ overnight. Immune reaction was revealed by goat anti-mouse IgG conjugated with biotin (1:200 dilution; Vector Laboratories) followed by incubation with ABC complex (1:200 dilution; Vector Laboratories), according to the manufacturer's instructions. Negative controls were carried out by omitting the primary or the secondary antibodies. The sections were counterstained with hematoxylin before mounting. 


\section{Ceramide Synthase Activity Assay}

Approximately $100 \mathrm{mg}$ of lung tissue homogenates were incubated with $\left[{ }^{3} \mathrm{H}\right]$ palmytic acid $(2.5 \mu \mathrm{Ci} / \mathrm{ml}$; Amersham, Buckinghamshire, UK) for $1 \mathrm{~h}$. Lipids were extracted with ice-cold methanol containing $2 \%$ acetic acid and 5\% chloroform and resolved using thin-layer chromatography. Lipids comigrating with standards were scraped and quantified by lipid scintillation counting. Ceramide was measured on the lipidic extracts using the diacyl-glycerol kinase assay. Lung ceramide content was expressed as disintegrations per minute per milligrams of proteins.

\section{DNA Nicking Assay for Apoptosis in Airway Epithelial Cells}

Lung tissue specimens from guinea pigs were evaluated for cell death by the in situ apoptosis detection kit AP (Roche Diagnostics, Indianapolis, IN), based on the terminal deoxynucleotidyl transferase (TdT)-mediated dUTP nick-end labeling (TUNEL) assay. Apoptotic cells in lung tissue sections were visualized by labeling DNA strand breaks by TdT, which catalyzes polymerization of labeled nucleotides to free 3 '-OH DNA ends in a template-independent manner. The detection of the incorporated fluorescein was carried out by an anti-fluorescein antibody conjugated with alkaline phosphatase, which is converted by Vector Red Alkaline Phosphatase Substrate K (Vector Laboratories) or by nitro blue tetrazolium (NBT)/5-bromo-4chloro-3-indolyl phosphate (Roche Diagnostics). From each biopsy, at least four bronchiolar profiles were evaluated under a light microscope at a $20 \times$ magnification for TUNEL-positive cells. The percentage is calculated as the number of positive cells per total number of bronchial epithelial cells.

\section{Determination of Caspase-3 Activity}

The activity of caspase-3 was determined using the Ac-Asp-GluVal-Asp-AMC (Ac-DEVD-AMC; Bachem, Bubendorf, Switzerland) fluorescent substrate, according to Stennicke and Salvesen (1997). Lung tissue samples were homogenized with $10 \mathrm{mM}$ HEPES, $\mathrm{pH}$ 7.4, containing $0.5 \% 3$-[(3-cholamidopropyl)dimethylammonio]-1propane-sulfonate, $42 \mathrm{mM} \mathrm{KCl}, 5 \mathrm{mM} \mathrm{MgCl}_{2}, 1 \mathrm{mM}$ dithiothreitol (DTT), $1 \mathrm{mM}$ phenylmethylsulfonyl fluoride, $2 \mu \mathrm{g} / \mathrm{ml}$ leupeptin, and $1 \mu \mathrm{g} / \mathrm{ml}$ pepstatin A. The homogenate was then centrifuged at $10,000 \mathrm{~g}$ for $10 \mathrm{~min}$. The supernatants (containing $250 \mu \mathrm{g}$ of total protein) were incubated with $40 \mu \mathrm{M}$ Ac-DEVD-AMC for $60 \mathrm{~min}$ at $37^{\circ} \mathrm{C}$. Substrate cleavage was monitored fluorometrically (Spectrofluo JY3 D; Jobin Yvon, Paris, France) at 380-nm excitation and 460-nm emission wavelengths. Data are expressed as arbitrary units per milligram of proteins. One unit of enzyme activity is defined as the amount of enzyme required to liberate $40 \mu \mathrm{mol}$ of Ac-DEVD-AMC upon $60 \mathrm{~min}$ at $37^{\circ} \mathrm{C}$.

\section{Determination of Lung Tissue Myeloperoxidase Activity}

Myeloperoxidase (MPO) activity, an indicator of leukocyte accumulation, was determined as described previously (Masini et al., 2005). Lung tissue samples of approximately $100 \mathrm{mg}$ were homogenized in a solution containing $0.5 \%$ hexadecyltrimethylammonium bromide dissolved in $10 \mathrm{mM}$ potassium phosphate buffer, $\mathrm{pH} 7$, and then centrifuged for $30 \mathrm{~min}$ at $20,000 \mathrm{~g}$ at $4^{\circ} \mathrm{C}$. An aliquot of the supernatant was then allowed to react with a solution of tetramethylbenzidine (1.6 mM; Sigma-Aldrich) and $0.1 \mathrm{mM} \mathrm{H}_{2} \mathrm{O}_{2}$. The rate of change in absorbance was measured spectrophotometrically at 650-nm wavelength. Myeloperoxidase activity was defined as the quantity of enzyme degrading $1 \mu \mathrm{mol}$ of hydrogen peroxide per minute at $37^{\circ} \mathrm{C}$ (expressed in milliunit per milligram of wet tissue).

\section{Determination of Lung Tissue Malonyldialdehyde Production}

This was determined by measurement of the chromogen obtained from the reaction of malonyldialdehyde (MDA) with 2-thiobarbituric acid (Masini et al., 2005). Approximately $100 \mathrm{mg}$ of lung tissue were homogenized with $1 \mathrm{ml}$ of $50 \mathrm{mM}$ Tris-HCl buffer containing $180 \mathrm{mM}$ $\mathrm{KCl}$ and $10 \mathrm{mM}$ EDTA, final $\mathrm{pH}$ 7.4. 2-Thiobarbituric acid $(0.5 \mathrm{ml}$, $1 \% \mathrm{w} / \mathrm{v}$; Sigma-Aldrich) in $50 \mathrm{mM} \mathrm{NaOH}$ and $0.5 \mathrm{ml}$ of $\mathrm{HCl}(25 \% \mathrm{w} / \mathrm{v}$ in water) was added to $0.5 \mathrm{ml}$ of sample. The mixture was placed in test tubes, sealed with screw caps, and heated in boiling water for 10 min. After cooling, the chromogen was extracted in $3 \mathrm{ml}$ of 1-butanol, and the organic phase was separated by centrifugation at $2000 \mathrm{~g}$ for $10 \mathrm{~min}$. The absorbance of the organic phase was read spectrophotometrically at 532-nm wavelength. The values are expressed as nanomole of thiobarbituric acid-reactive substances (MDA equivalents) per milligram of protein, using a standard curve of 1,1,3,3tetramethoxypropane (Sigma-Aldrich).

\section{Determination of 8-Hydroxy-2' -deoxyguanosine}

DNA isolation was performed according to Masini et al. (2005). Lung samples were homogenized in $1 \mathrm{ml}$ of $10 \mathrm{mM}$ PBS, pH 7.4, sonicated on ice for $1 \mathrm{~min}$, added with $1 \mathrm{ml}$ of $10 \mathrm{mM}$ Tris-HCl buffer, $\mathrm{pH}$ 8, containing $10 \mathrm{mM}$ EDTA, $10 \mathrm{mM} \mathrm{NaCl}$, and 0.5\% SDS, incubated for $1 \mathrm{~h}$ at $37^{\circ} \mathrm{C}$ with $20 \mu \mathrm{g} / \mathrm{ml}$ RNase I (Sigma-Aldrich), and incubated overnight at $37^{\circ} \mathrm{C}$ under argon in the presence of 100 $\mu \mathrm{g} / \mathrm{ml}$ proteinase $\mathrm{K}$ (Sigma-Aldrich). The mixture was extracted with chloroform/isoamyl alcohol (10/2 v/v). DNA was precipitated from the aqueous phase with 0.2 volumes of $10 \mathrm{M}$ ammonium acetate, solubilized in $200 \mu \mathrm{l}$ of $20 \mathrm{mM}$ acetate buffer, $\mathrm{pH} 5.3$, and denatured at $90^{\circ} \mathrm{C}$ for $3 \mathrm{~min}$. The extract was then supplemented with $10 \mathrm{IU}$ of P1 nuclease (Sigma-Aldrich) in $10 \mu \mathrm{l}$ and incubated for $1 \mathrm{~h}$ at $37^{\circ} \mathrm{C}$ with $5 \mathrm{IU}$ of alkaline phosphatase (Sigma-Aldrich) in $0.4 \mathrm{M}$ phosphate buffer, $\mathrm{pH}$ 8.8. All of the procedures were performed in the dark under argon. The mixture was filtered by an Amicon Micropure-EZ filter (Millipore Corporation, Billerica, MA), and $50 \mu \mathrm{l}$ of each sample was used for 8-hydroxy-2'-deoxyguanosine (8-OHdG) determination using a Bioxytech enzyme immunoassay kit (Oxis, Portland, OR), following the instructions provided by the manufacturer. The values are expressed as nanogram of 8-OHdG per milligram of protein.

\section{Measurement of MnSOD Activity}

Lung samples were homogenized with $10 \mathrm{mM}$ PBS, pH 7.4, sonicated on ice for $1 \mathrm{~min}$, and centrifuged at $100 \mathrm{~g}$ for $10 \mathrm{~min}$. The assay of MnSOD activity was performed on the supernatants by the method described by Masini et al. (2005). The assay is based on SOD-induced inhibition of the conversion of NBT into a blue tetrazolium salt mediated by superoxide radicals generated by xanthine oxidase. The reaction was performed in sodium carbonate buffer (50 $\mathrm{mM}$ ), $\mathrm{pH}$ 10.1, containing $0.1 \mathrm{mM}$ EDTA, $25 \mu \mathrm{M}$ NBT (SigmaAldrich), $0.1 \mathrm{mM}$ xanthine, and $2 \mathrm{nM}$ xanthine oxidase (Roche Diagnostics). The rate of reduction of NBT was monitored with a PerkinElmer spectrophotometer set (PerkinElmer Life and Analytical Sciences, Boston, MA) at 560-nm wavelength. The amount required to inhibit the rate of reduction of NBT by $50 \%$ was defined as 1 unit of SOD activity. Specific MnSOD activity was calculated by inhibiting total SOD activity preincubating the sample for $30 \mathrm{~min}$ with $2 \mathrm{mM}$ sodium cyanide. Values are expressed as milliunits per milligram of proteins.

\section{Measurement of PARP Activity}

PARP-1 activity was measured as described previously (Suzuki et al., 2004). Lung tissues were homogenized in $50 \mathrm{mM}$ Tris-HCI, $\mathrm{pH} 8$, $4^{\circ} \mathrm{C}$, containing $0.1 \%$ Nonidet P- $40,200 \mathrm{mM} \mathrm{KCl}, 2 \mathrm{mM} \mathrm{MgCl}_{2}, 50$ $\mu \mathrm{M} \mathrm{ZnCl}, 2 \mathrm{mM}$ DTT, and protease inhibitors (1 mM phenylmethylsulfonyl fluoride, $5 \mu \mathrm{l} / \mathrm{ml}$ leupeptin and antipain). Samples were then centrifuged, and $10 \mu \mathrm{l}$ of each supernatant were incubated for 5 min at $25^{\circ} \mathrm{C}$ with $2 \mu \mathrm{l}$ of $\left[{ }^{3} \mathrm{H}\right] \mathrm{NAD}^{+}$(specific activity $25 \mathrm{Ci} / \mathrm{nmol}$; Amersham) in $50 \mathrm{mM}$ Tris-HCI, $\mathrm{pH} 8$, containing $20 \mathrm{mM} \mathrm{MgCl}_{2}, 1$ $\mathrm{mM}$ DTT, and $20 \mu \mathrm{M} \mathrm{NAD}^{+}$in the absence or presence of activated calf thymus DNA in the final volume of $100 \mu$ l. The reaction was stopped by the addition of $5 \%$ trichloroacetic acid. Samples were filtered, and the radioactivity in the acid-insoluble fraction was 
counted by a Beckman LS1801 liquid scintillation spectrometer. PARP activity estimated without activated DNA in the mixture was assigned as "endogenous" activity. Activity estimated in the presence of activated DNA in the assay mixture was assigned as "total" activity of PARP. Ratio between endogenous and total activity was considered as the measure of PARP activity in the tissues.

\section{Determination of $\mathrm{PGD}_{2}$ and TNF- $\alpha$ in Bronchoalveolar Lavage Fluid}

Production of $\mathrm{PGD}_{2}$, the major cyclooxygenase product generated by activated mast cells during allergic response, and TNF- $\alpha$ were measured using a commercial enzyme-linked immunosorbent assay kits (Cayman Chemical, Ann Arbor, MI), following the protocol provided by the manufacturer. Results are expressed as nanogram of $\mathrm{PGD}_{2}$ on $\mathrm{TNF} \alpha$ per milliliter of bronchoalveolar lavage fluid.

\section{Statistical Analysis}

Data are expressed as mean \pm S.E.M. Statistical analysis was performed by one-way analysis of variance, followed by the Student's-Newman-Keuls multiple comparison post-hoc test; $p<0.05$ was considered significant. Calculations were done using a GraphPad Prism 2.0 statistical program (GraphPad Software, San Diego, CA).

\section{Results}

Ceramide Contributes to Respiratory Abnormalities and Hyper-Responsiveness in Actively Sensitized Guinea Pigs. As detected by immunohistochemistry, aerosol administration of OVA increased lung ceramide levels in sensitized but not in naive guinea pigs (Fig. 1, A and B). Staining for ceramide was stronger in the airway epithelium (Fig. 1B). Increased ceramide was paralleled by up-regulation of ceramide synthase activity (Fig. 2) and was associated with marked abnormalities in the respiratory pattern, consisting of a significant reduction of cough latency and onset of dyspnea (Fig. 3A) and a significant increase in cough severity score (Fig. 3B). Likewise, experiments with mechanically ventilated animals revealed that, in sensitized but not naive animals, OVA challenge induced a prompt, clear-cut increase in inflation pressure (PAO), indicating the occurrence of an immediate asthmatic response (Fig. 3C). Such functional abnormalities were accompanied by histopathological abnormalities. A representative micrograph of lung tissue is shown in Fig. 4A. Indeed, macroscopic examination of the lungs showed prominent changes consisting mainly of marked swelling of the pulmonary lobes due to air accumulation.

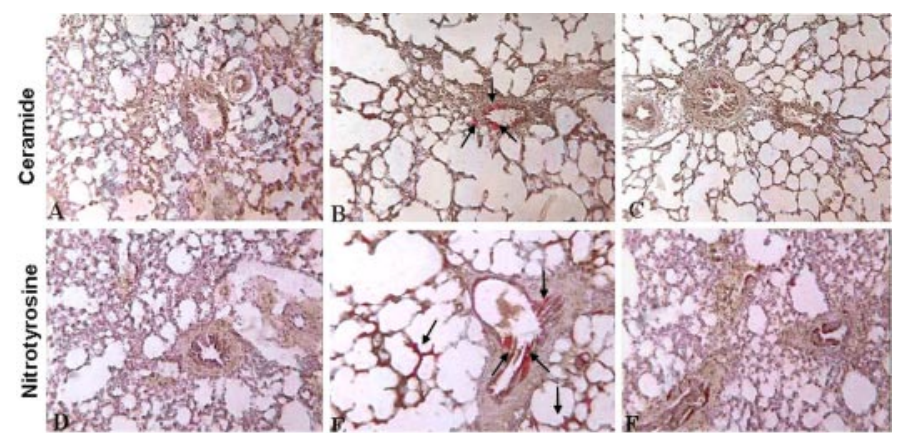

Fig. 1. Compared to OVA-challenged naive animals (A and D), OVA challenge in sensitized guinea pigs pretreated with PBS leads to formation of ceramide and nitrotyrosine, as detected by immunohistochemistry (B and E). Pretreatment with FB1 (1 mg/kg) before OVA challenge blocks ceramide staining $(\mathrm{C}$ and $\mathrm{F})$. Images are representative of at least three different experiments.

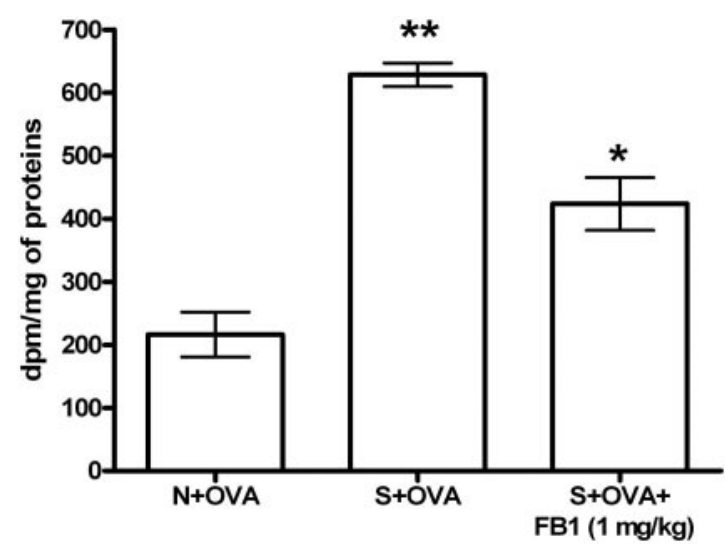

Fig. 2. Ceramide synthase activity in lung tissue homogenates is upregulated in OVA-challenged, sensitized guinea pigs (S+OVA) compared with OVA-challenged naive animals (N+OVA). FB1 pretreatment of OVA-challenged, sensitized animals significantly reduces the enzyme activity. Values are mean \pm S.E.M. of four different experiments. $*, p<$ 0.01 versus $\mathrm{N}+\mathrm{OVA}$; **, $p<0.001$ versus $\mathrm{S}+\mathrm{OVA}$.

Sectioning of trachea or of main bronchi did not cause lung deflation, thus indicating that obstruction of peripheral bronchi had occurred. Light microscopy of lung tissue showed that the intrapulmonary bronchioli and respiratory air spaces of naive guinea pigs had a normal appearance. In particular, intrapulmonary bronchioli showed open lumina, with bronchial mucosa forming short folds, and alveolar air spaces were evenly small-sized (Fig. 4A, panel A). On the other hand, in the sensitized, vehicle-treated guinea pigs challenged with OVA, we observed a reduction of the lumen of intrapulmonary bronchi and, in large areas of the lung parenchyma, a marked dilation of the alveolar air spaces due to accumulation of entrapped air (Fig. 4A, panel B). Furthermore and as shown by morphometric analysis, the luminal area of the alveolar air spaces was significantly increased, whereas the bronchiolar area was significantly reduced postantigen challenge in sensitized animals (Fig. 4C).

Inhibition of de novo ceramide synthesis with FB1 (1 mg/ $\mathrm{kg}$ ), a competitive and reversible inhibitor of ceramide synthase (Petrache et al., 2005), attenuated the formation of ceramide as measured by immunohistochemistry (Fig. 1C). In keeping with these results, OVA challenge in sensitized guinea pigs increased the enzymatic activity of ceramide synthase, and FB1 pretreatment significantly reduced this phenomenon (Fig. 2). FB1 also improved in a dose-dependent manner $(0.25-1 \mathrm{mg} / \mathrm{kg}$ ) the respiratory abnormalities (Fig. 3, $\mathrm{A}$ and $\mathrm{B}$ ), attenuated hyper-responsiveness (Fig. 3C), and improved overall histopathological abnormalities (Fig. 4, A-C). Thus, as can be seen in Fig. 4A (panel C), the intrapulmonary bronchi did not show appreciable signs of constriction, and the alveolar air spaces were not dilated. Morphometric analysis confirmed the visual observations that FB1 prevented in a dose-dependent manner $(0.25-1 \mathrm{mg} / \mathrm{kg})$ bronchiolar constriction and pulmonary air space inflation (Fig. 4, $\mathrm{B}$ and $\mathrm{C}$ ).

Ceramide Inhibition Attenuates Oxidative and Nitrosative Stress. Ceramide increased concurrently with markers of oxidative and nitrosative stress as evidenced by the appearance in lung tissues of nitrotyrosine, an indicator of the formation of nitrating oxidants (Fig. 1E), and by the increased formation of MDA (Fig. 5A), a well known byproduct of oxidative stress-induced lipid peroxidation of cell mem- 

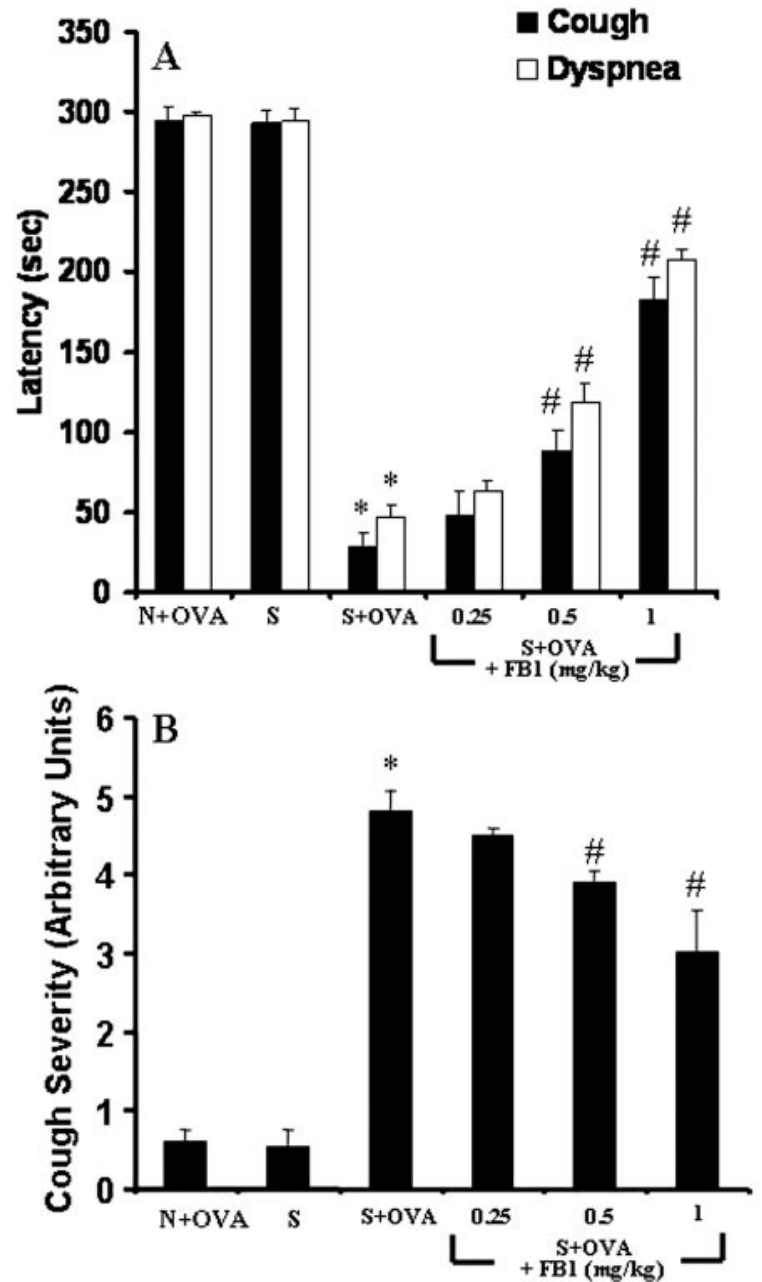

C

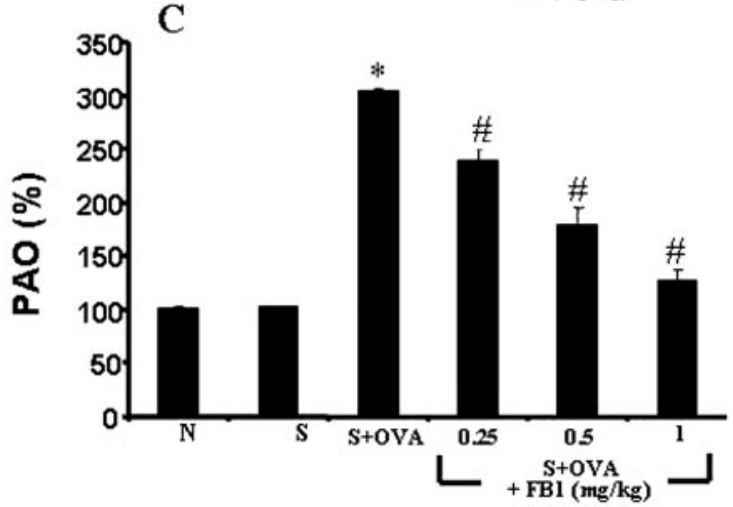

Fig. 3. Compared to OVA-challenged naive (N+OVA) or in sensitized and unchallenged (S) animals, OVA challenge in sensitized guinea pigs (S+OVA) led to a reduction of the latency time for cough and dyspnea (A) and to an increase in cough severity (B). As shown in C, FB1 also inhibited in a dose-dependent manner $(0.25-1 \mathrm{mg} / \mathrm{kg})$ OVA-induced bronchoconstriction in sensitized, mechanically ventilated guinea pigs, evaluated $10 \mathrm{~min}$ after OVA aerosol. PAO is expressed as percentage change over basal inflation pressure before OVA challenge, assumed as $100 \%$. Data are expressed as mean \pm S.E.M. of five animals per experimental group. $*, p<0.01$ versus OVA-challenged naive animals; \#, $p<0.01$ versus OVA-challenged, sensitized animals in the absence of FB1 or unchallenged, sensitized animals.

branes. Furthermore, OVA challenge led to enzymatic inactivation of MnSOD (Fig. 5B), increased the levels of 8-OHdG (Fig. 5C), a marker of oxidative DNA damage, and increased PARP activity (Fig. 5D). FB1 (1 mg/kg) attenuated nitroty-
A

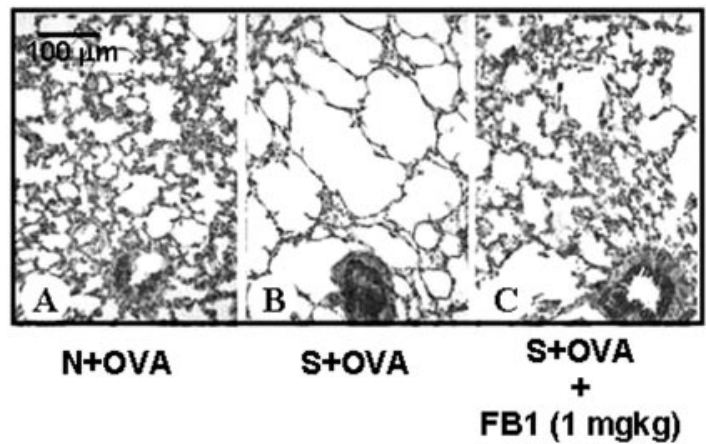

B

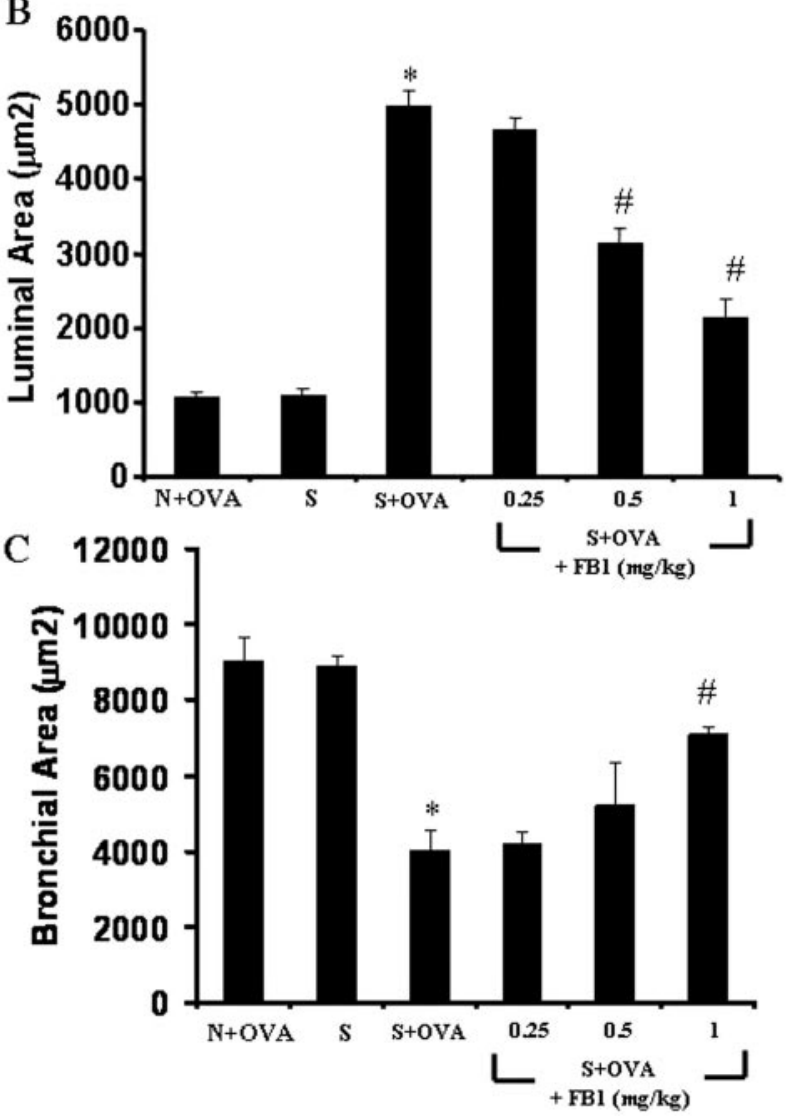

Fig. 4. A, representative lung tissue micrographs from OVA-challenged, naive guinea pigs (panel A), OVA-challenged, sensitized guinea pigs pretreated with PBS (panel B) and OVA-challenged, sensitized guinea pigs pretreated with the highest dose of FB1 $(1 \mathrm{mg} / \mathrm{kg}$ ) (panel C). Compared with $\mathrm{A}$, a marked dilation of respiratory air spaces and reduction of bronchiolar lumen is seen in $\mathrm{B}$ but these alterations are not present in the FB1-treated group (C). Hematoxylin and eosin staining. B and C, morphometric analysis of luminal area of respiratory air spaces (B) and bronchioli (C). FB1 dose-dependently reduces the lung tissue abnormalities induced by OVA challenge in sensitized guinea pigs. $*, p<0.001$ versus naive animals; \#, $p<0.001$ versus OVA-challenged, sensitized animals.

rosine formation (Fig. $1 \mathrm{~F})$ and dose-dependently $(0.25-1 \mathrm{mg} /$ $\mathrm{kg}$ ) restored the enzymatic activity of MnSOD and decreased oxidative DNA damage, PARP activity, and MDA formation (Fig. 5, A-D).

Ceramide Inhibition Attenuates Apoptosis. OVA challenge in sensitized animals increases the activity of caspase-3 (Fig. 6), supporting the presence of apoptosis. Indeed, no TUNEL-positive cells were detected in OVA-challenged naive animals (Fig. 7A), whereas OVA challenge in sensitized guinea pigs led to the appearance of several airway epithelial cells 

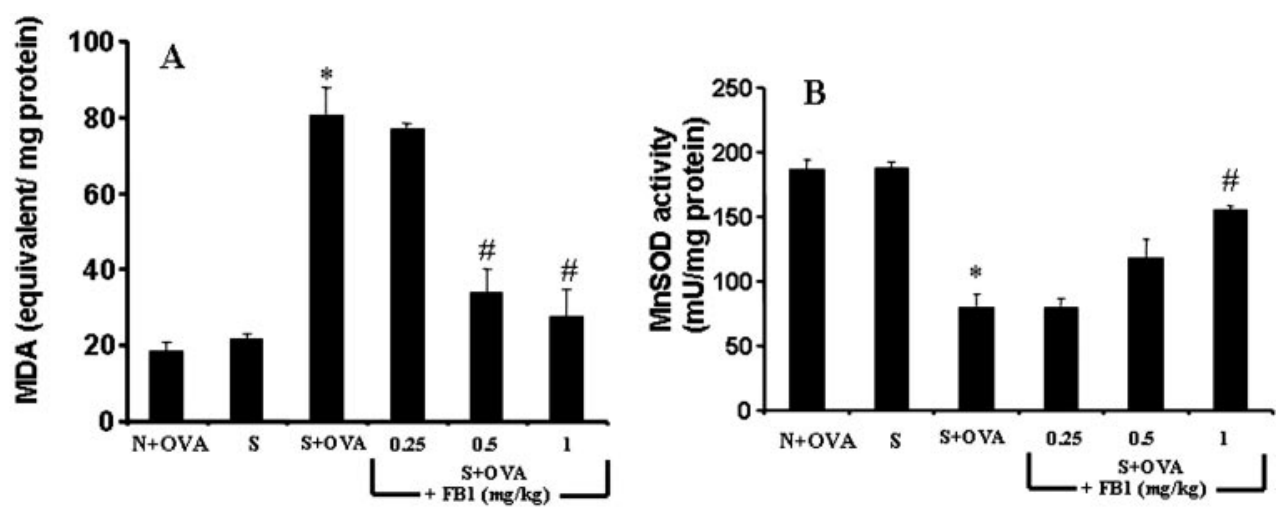

Fig. 5. Compared to OVA-challenged naive (N+OVA) or sensitized and unchallenged (S) animals, OVA challenge in sensitized guinea pigs (S+OVA) leads to increased formation of MDA (A), inactivation of MnSOD (B), enhanced generation of 8-OHdG (C), and increased PARP activity (D). These biochemical changes are reduced in a dosedependent fashion by FB1 $(0.25-1 \mathrm{mg} /$ $\mathrm{kg})$. Data are expressed as mean \pm S.E.M. of five animals per experimental group. $*, p<0.01$ versus OVA-challenged naive animals; $\#, p<0.05$ versus OVA-challenged, sensitized animals in the absence of FB1 or non-OVAchallenged, sensitized animals.
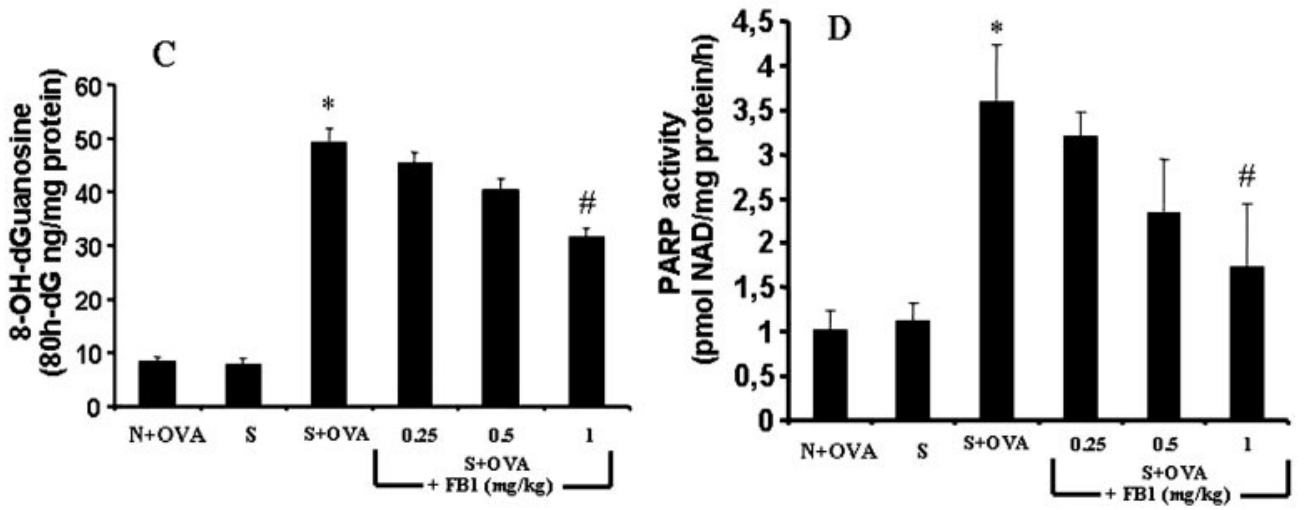

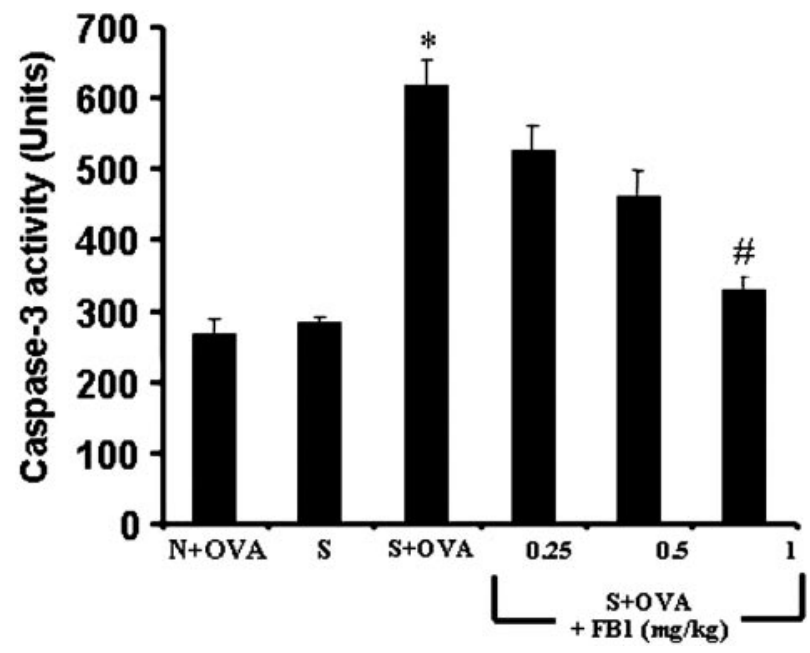

Fig. 6. Compared to OVA-challenged naive (N+OVA) or in sensitized and unchallenged (S) animals, OVA challenge in sensitized guinea pigs (S+OVA) increased caspase-3 activity, and this was blocked in a dosedependent fashion by FB1 $(0.25-1 \mathrm{mg} / \mathrm{kg})$. Data are expressed as mean \pm S.E.M. of five animals per experimental group. $*, p<0.01$ versus OVAchallenged, naive animals; $\#, p<0.05$ versus OVA-challenged, sensitized animals in the absence of FB1 or sensitized, unchallenged animals.

undergoing apoptosis (Fig. 7, B and D). FB1 attenuated in a dose-dependent fashion $(0.25-1 \mathrm{mg} / \mathrm{kg})$ caspase-3 activation (Fig. 6) and significantly reduced epithelial cell apoptosis (0.5-1 $\mathrm{mg} / \mathrm{kg}$ ) (Fig. 7, A and B).

Ceramide Inhibition Attenuates Inflammation. Compared to naive and OVA-challenged animals, the increase in ceramide observed in sensitized animals after OVA challenge was associated with a clear-cut inflammatory response characterized by mast cell degranulation (Fig. 8A) and neu-
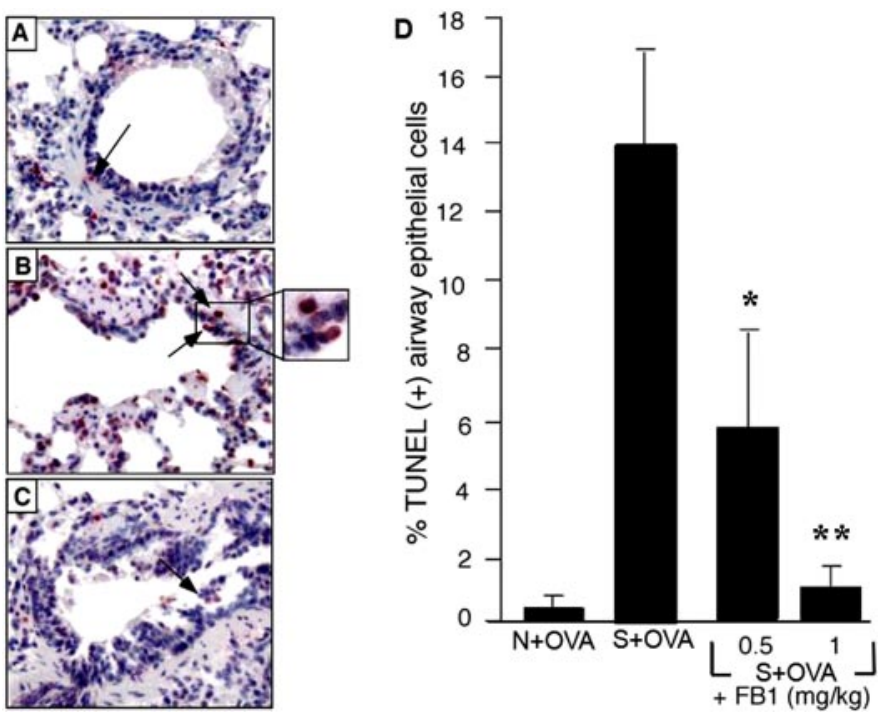

Fig. 7. Immunohistochemical analysis of apoptosis in airway epithelial cells. Increased numbers of TUNEL-positive epithelial cells can be seen (red nuclei) in OVA-challenged, sensitized animals (B) compared with OVA-challenged naive animals (A). FB1 $(0.5-1 \mathrm{mg} / \mathrm{kg})$ leads to a reduction of the amount of TUNEL-positive cells (C). The histogram (D) shows the mean \pm S.E.M. of percent TUNEL-positive epithelial cells. $*, p<$ $0.05 ; * *, p<0.01$.

trophilic and eosinophilic infiltration in lung tissue, as measured by increases in MPO levels and MBP-positive cells, respectively (Fig. 8, B and C). Inflammatory cells were mostly located around the bronchi and within the stromal septa. Antigen challenge also led to increased levels of $\mathrm{PGD}_{2}$, the major mast cell-derived prostaglandin, in bronchoalveolar lavage fluids and of TNF- $\alpha$, a proinflammatory cytokine 


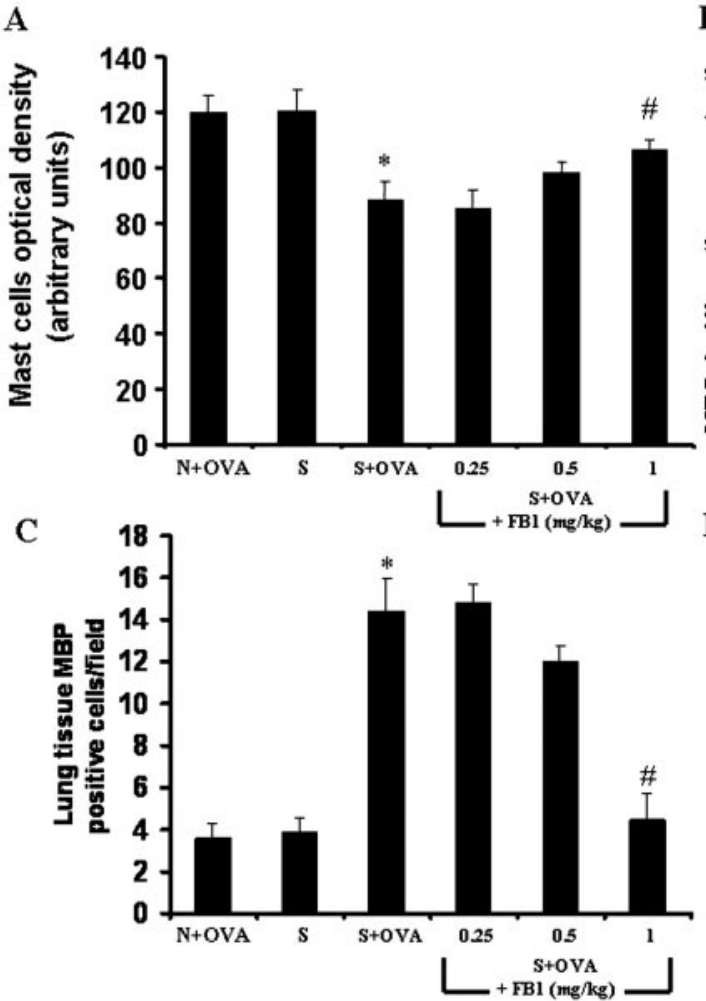

(Fig. 8D). The above signs of inflammatory response were consistently reduced by FB1 in a dose-dependent fashion (0.25-1 mg/kg) (Fig. 8, A-D).

\section{Discussion}

Asthma is a chronic inflammatory disease of the airways affecting 6 to $7 \%$ in the population and accounting for more than $\$ 6.2$ billion in direct and indirect costs in the United States alone (Busse and Lemanske, 2001). The pathophysiology of this disease is complex and not completely clarified, thus being the object of intensive research efforts. The results of our studies implicate ceramide as a key signaling mediator in biochemical events culminating in acute asthmatic response and airway inflammation and, ultimately, respiratory dysfunction.

Antigen challenge in sensitized but not naive guinea pigs increased ceramide synthase activity, and the amount of immunoreactive ceramide in lung tissues, preferentially within the epithelium, reduced the latency for cough and dyspnea and significantly increased cough severity. This increase in ceramide was associated with the appearance in lung tissues of nitrotyrosine, an indicator of the formation of nitrating oxidants, and by increased formation of MDA, a byproduct of oxidative stress-induced lipid peroxidation of cell membranes. Systemic administration of the ceramide synthase inhibitor FB1 attenuated the formation of ceramide and significantly reduced the development of oxidative/nitrosative stress and respiratory abnormalities. These data provide a link between ceramide, oxidative/nitrosative stress, and acute asthmatic response.

Oxidative and nitrosative stress is a key feature of asthma, and as such, the prominent roles of superoxide, nitric oxide, and their reaction product peroxynitrite are well recognized
(Comhair et al., 2005). It is noteworthy that we and others have demonstrated an inverse correlation between production of these reactive species and forced expiration volume, an index of bronchial obstruction, in asthmatics (Calhoun et al., 1992; Comhair et al., 2005). A key signaling pathway that favors accumulation of superoxide and thus peroxynitrite is the enzymatic inactivation of MnSOD (Radi et al., 2001) that normally degrades superoxide. MnSOD is itself a target for tyrosine nitration and oxidation (Yamakura et al., 1998) that leads to loss of enzyme function, subsequent oxidative damage of mitochondrial proteins, and initiation of apoptosis. Under severe oxidative and nitrosative stress, DNA damage causes overactivation of the nuclear enzyme PARP, a critical intracellular mechanism of cell death through both necrotic and apoptotic pathways (Schreiber et al., 2006). Here we have shown that FB1 blocked the inactivation of MnSOD and prevented oxidative DNA damage, PARP and caspase-3 activation, and epithelial cell apoptosis. The importance of the reduction of epithelial cell apoptosis by FB1 is underscored by the fact that apoptosis has been intimately linked to airway remodeling and hyper-responsiveness in asthmatics (Comhair et al., 2005). Taken together, our results suggest that ceramide induces oxidative/nitrosative stress, resulting in MnSOD inactivation, thus triggering epithelial cell apoptosis, presumably via PARP and caspase activation. Ceramide has been reported to stimulate formation of reactive oxygen/nitrogen species and to also induce the expression of the inducible nitric-oxide synthase (Won et al., 2004). It is interesting to note that, whereas ceramide promotes generation of these species, superoxide and nitric oxide (and presumably peroxynitrite) increase steady-state concentrations of ceramide by activating sphingomyelinases and by increasing the degradation of ceramidases, the enzymes responsible for ceramide catabolism (Huwiler et al., 2000; Pautz et al., 
2002). These events contribute to the overall increase in the levels of ceramide and thus ceramide-mediated damage. Although the mechanisms by which these reactive oxygen/nitrogen species enhance the degradation of ceramidases are not understood, one potential mechanism may be nitration, thus facilitating their faster degradation by the ubiquitin/ proteasome pathway (Souza et al., 2000). In endothelial cells, costimulation with nitric oxide and superoxide synergistically increase ceramide production and apoptosis (Pettus et al., 2002), which may contribute to an overall increase in tissue levels of ceramide and thus ceramide-mediated damage.

Our results suggest that the protective effects of FB1 may be secondary to attenuation of the inflammatory response, as evidenced by reductions of mast cell activation and degranulation, neutrophil and eosinophil infiltration, and release of TNF- $\alpha$. The critical roles of neutrophils, eosinophils, and proinflammatory cytokines in the pathogenesis of asthma are known. Inhibition of neutrophil and eosinophil infiltration attenuates inflammation associated with late-phase responses and airway hyper-responsiveness, whereas mast cell mediators, including histamine, $\mathrm{PGD}_{2}$ and $\mathrm{TNF}-\alpha$, evoke bronchoconstriction, smooth muscle cell proliferation, and recruitment of inflammatory cells (Busse and Lemanske, 2001). Ceramide modulation of these inflammatory responses through oxidative/nitrosative stress may occur upon several mechanisms. First, superoxide and peroxynitrite induce endothelial cell damage and increased microvascular permeability (Haglind et al., 1994) and activate redox-sensitive NF- $\kappa \mathrm{B}$ and AP-1 that promote the expression of genes encoding for proinflammatory and pro-nociceptive cytokines, such as IL- $1 \beta$, TNF- $\alpha$, and IL-6 (Ndengele et al., 2005), as well as for adhesion molecules involved in neutrophil and eosinophil recruitment to inflammatory sites (Salvemini et al., 1999). Second, superoxide/peroxynitrite promote mast cell degranulation and histamine release (Masini et al., 2005). Third, superoxide/peroxynitrite activate cyclooxygenase enzymes leading to increased production of prostaglandins. Fourth, thera-

peutic reduction of oxidative/nitrosative stress with superoxide dismutase mimetics and peroxynitrite decomposition catalysts is anti-inflammatory and tissue-protective (Salvemini et al., 1999).

In summary, our results have revealed that formation of ceramide in the lung plays a critical role in the development of allergic asthma through at least three biochemical pathways: 1) oxidative and nitrosative stress; 2) apoptosis of airway epithelial cells; and 3) local tissue inflammation. Our study does not provide direct evidence that some of the observed effects could be ascribed to the downstream ceramide metabolite $\mathrm{S} 1 \mathrm{P}$, although this possibility is not to be ruled out. S1P is stored in mast cells, platelets, and endothelial and epithelial cells (Jolly et al., 2002) and is secreted as an autocrine mediator into the extracellular environment. S1P activates monocytes, endothelial cells, mast cells, and smooth muscle cells, mediates eosinophil and lymphocyte infiltration, and promote airway remodeling and hyper-responsiveness (Lee et al., 1999; Ammit et al., 2001; Roviezzo et al., 2007). In this context, S1P levels increase in the airways of asthmatic patients after allergen challenge and correlate with eosinophil number and protein concentration in their bronchoalveolar lavage fluids (Roviezzo et al., 2004). Multi- ple $\mathrm{S} 1 \mathrm{P}$ receptors have been identified in the lung, including $\mathrm{S} \mathrm{Pr}_{1}$ and $\mathrm{S}_{1} \mathrm{Pr}_{3}$ (Zhang et al., 1999). Recent studies in $\mathrm{S} \mathrm{Pr}_{3}$-deficient mice suggested that $\mathrm{S} 1 \mathrm{Pr}_{3}$ receptors expressed by the bronchial epithelium are responsible for S1Pmediated pulmonary leakage (Gon et al., 2005). Knowledge of the relative contribution of each $\mathrm{S} 1 \mathrm{P}$ receptor through the development of selective inhibitors will be critical in understanding its importance in asthma. Nevertheless, therapeutic strategies aimed at lowering pathologically elevated concentrations of ceramide in asthma could prevent the formation of both ceramide and $\mathrm{S} 1 \mathrm{P}$, possibly providing a more favorable endpoint than simply blocking one of the S1P receptors.

Our data suggest that increased formation of ceramide after antigen challenge promotes oxidative/nitrosative stress and enzymatic inactivation of MnSOD that trigger apoptosis and loss of airway epithelial cells. Furthermore, ceramide contributes to the lung inflammatory response by degranulating mast cells, recruiting neutrophils/eosinophils, and increasing formation of cytokines. In this paradigm, it is important to consider that reciprocal relationships exist among the inflammatory response, oxidative stress, and activation of the ceramide pathway, which may sparkle a vicious cycle that amplifies the disease. In turn, cytokines can stimulate the formation of reactive oxidative/nitrosative species and activate the de novo ceramide synthesis pathway (Kolesnik, 2002). The current findings suggest that strategies aimed at reducing in situ levels of ceramide could interrupt this vicious cycle and be a novel, promising antiasthmatic therapeutic strategy.

\section{Acknowledgments}

We thank Dr. A. J. Lechner (Department of Pharmacological and Physiological Sciences, St. Louis University School of Medicine) and Prof. D. Bani (Department of Anatomy, Histology and Forensic Medicine, University of Florence School of Medicine, Florence, Italy) for invaluable input.

\section{References}

Ammit AJ, Hastie AT, Edsal LC, Hoffman RK, Amrani Y, Krymskaya VP, Kane SA, Peters SP, Penn RB, Spiegel S, et al. (2001) Sphingosyne-1-phosphate modulates human airway smooth muscle cell functions that promote inflammation and airway remodeling in asthma. FASEB J 15:1212-1214.

Andreadis AA, Hazen SL, Comhair SA, and Erzurum SC (2003) Oxidative and nitrosative events in asthma. Free Radic Biol Med 35:213-225.

Barnes PJ (2004) New drugs for asthma. Nat Rev Drug Discov 3:831-844.

Busse WW and Lemanske RF Jr (2001) Asthma. N Engl J Med 344:350-362.

Calhoun WJ, Reed HE, Moest DR, and Stevens CA (1992) Enhanced superoxide production by alveolar macrophages and air-space cells, airway inflammation, and alveolar macrophage density changes after segmental antigen bronchoprovocation in allergic subjects. Am Rev Respir Dis 145:317-325.

Chalfant CE, Rathman K, Pinkerman RL, Wood RE, Obeid LM, Ogretmen B, and Hannun YA (2002) De novo ceramide regulates the alternative splicing of caspase 9 and Bcl-x in A549 lung adenocarcinoma cells. Dependence on protein phosphatase-1. J Biol Chem 277:12587-12595.

Chun J, Goetzl EJ, Hla T, Igarashi Y, Lynch KR, Moolenaar W, Pyne S, and Tigyi G (2002) International union of pharmacology. XXXIV. Lysophospholipid receptor nomenclature. Pharmacol Rev 54:265-269.

Comhair SA, Xu W, Ghosh S, Thunnissen FB, Almasan A, Calhoun WJ, Janocha AJ, Zheng L, Hazen SL, and Erzurum SC (2005) Superoxide dismutase inactivation in pathophysiology of asthmatic airway remodeling and reactivity. Am J Pathol 166:663-674.

Delogu G, Famularo G, Amati F, Signore L, Antonucci A, Trinchieri V, Di Marzio L and Cifone MG (1999) Ceramide concentrations in septic patients: a possible marker of multiple organ dysfunction syndrome. Crit Care Med 27:2413-2417.

Goggel R, Winoto-Morbach S, Vielhaber G, Imai Y, Lindner K, Brade L, Brade H, Ehlers S, Slutsky AS, Schutze S, et al. (2004) Paf-mediated pulmonary edema: a new role for acid sphingomyelinase and ceramide. Nat Med 10:155-160.

Gon Y, Wood MR, Kiosses WB, Jo E, Sanna MG, Chun J, and Rosen H (2005) S1p3 receptor-induced reorganization of epithelial tight junctions compromises lung barrier integrity and is potentiated by TNF. Proc Natl Acad Sci U S A 102:92709275.

Haglind E, Xia G, and Rylander R (1994) Effects of antioxidants and Paf receptor antagonist in intestinal shock in the rat. Circ Shock 42:83-91.

Heinrich M, Wickel M, Winoto-Morbach S, Schneider-Brachert W, Weber T, Brunner 
J, Saftig P, Peters C, Kronke M, and Schutze S (2000) Ceramide as an activator lipid of cathepsin D. Adv Exp Med Biol 477:305-315.

Huwiler A, Kolter T, Pfeilschifter J, and Sandhoff K (2000) Physiology and pathophysiology of sphingolipid metabolism and signaling. Biochim Biophys Acta 1485: 63-99.

Jolly PS, Rosenfeldt HM, Milstien S, and Spiegel S (2002) The roles of sphingosine1-phosphate in asthma. Mol Immunol 38:1239-1245.

Kolesnick R (2002) The therapeutic potential of modulating the ceramide/ sphingomyelin pathway. J Clin Invest 110:3-8.

Kolesnick R and Golde DW (1994) The sphingomyelin pathway in tumor necrosis factor and interleukin-1 signalling. Cell 77:325-328.

Kolesnick R and Fuks Z (2003) Radiation and ceramide-induced apoptosis. Oncogene 22:5897-5906

Lee MJ, Thangada S, Claffey KP, Ancellin N, Liu CH, Kluk M, Volpi M, Sha'afi RI, and Hla T (1999) Vascular endothelial cell adherens junction assembly and morphogenesis induced by sphingosine-1-phosphate. Cell 99:301-312.

Le Stunff H, Milstien S, and Spiegel S (2004) Generation and metabolism of bioactive sphingosine-1-phosphate. J Cell Biochem 92:882-899.

Masini E, Bani D, Vannacci A, Pierpaoli S, Mannaioni PF, Comhair SA, Xu W, Muscoli C, Erzurum SC, and Salvemini D (2005) Reduction of antigen-induced respiratory abnormalities and airway inflammation in sensitized guinea pigs by a superoxide dismutase mimetic. Free Radic Biol Med 39:520-531.

Ndengele MM, Muscoli C, Wang ZQ, Doyle TM, Matuschak GM, and Salvemini D (2005) Superoxide potentiates NF- $\kappa$ B activation and modulates endotoxin-induced cytokine production in alveolar macrophages. Shock 23:186-193.

Newton R, Hart L, Chung KF, and Barnes PJ (2000) Ceramide induction of COX-2 and $\mathrm{PGE}_{2}$ in pulmonary A549 cells does not involve activation of NF- $\kappa$ B. Biochem Biophys Res Commun 277:675-679.

Pautz A, Franzen R, Dorsch S, Boddinghaus B, Briner VA, Pfeilschifter J, and Huwiler A (2002) Cross-talk between nitric oxide and superoxide determines ceramide formation and apoptosis in glomerular cells. Kidney Int 61:790-796.

Petrache I, Natarajan V, Zhen L, Medler TR, Richter AT, Cho C, Hubbard WC, Berdyshev EV, and Tuder RM (2005) Ceramide upregulation causes pulmonary cell apoptosis and emphysema-like disease in mice. Nat Med 11:491-498.

Pettus BJ, Chalfant CE, and Hannun YA (2002) Ceramide in apoptosis: an overview and current perspectives. Biochim Biophys Acta 1585:114-125.

Radi R, Peluffo G, Alvarez MN, Naviliat M, and Cayota A (2001) Unraveling peroxynitrite formation in biological systems. Free Radic Biol Med 30:463-488.

Roviezzo F, Del Galdo F, Abbate G, Bucci M, D’Agostino B, Antunes E, De Dominicis G, Parente L, Rossi F, Cirino G, et al. (2004) Human eosinophil chemotaxis and selective in vivo recruitment by sphingosine 1-phosphate. Proc Natl Acad Sci U S A 101:11170-11175.
Roviezzo F, Di Lorenzo A, Bucci M, Brancaleone V, Vellecco V, De Nardo M, Orlotti D, De Palma R, Rossi F, D'Agostino B, et al. (2007) Sphingosine-1-phosphate/ sphingosine kinase pathway is involved in mouse airway hyper-responsiveness. Am J Respir Cell Mol Biol 36:757-762.

Salvemini D, Riley DP, Lennon PJ, Wang ZQ, Currie MG, Macarthur H, and Misko TP (1999) Protective effects of a superoxide dismutase mimetic and peroxynitrite decomposition catalysts in endotoxin-induced intestinal damage. $\mathrm{Br} \mathrm{J}$ Pharmacol 127:685-692.

Schreiber V, Dantzer F, Ame JC, and de Murcia G (2006) Poly(ADP-ribose): novel functions for an old molecule. Nat Rev Mol Cell Biol 7:517-528.

Siskind LJ, Kolesnick RN, and Colombini M (2002) Ceramide channels increase the permeability of the mitochondrial outer membrane to small proteins. J Biol Chem 277:26796-26803.

Souza JM, Choi I, Chen Q, Weisse M, Daikhin E, Yudkoff M, Obin M, Ara J, Horwitz J, and Ischiropoulos H (2000) Proteolytic degradation of tyrosine nitrated proteins. Arch Biochem Biophys 380:360-366.

Spiegel S and Milstien S (2003) Sphingosine-1-phosphate: an enigmatic signalling lipid. Nat Rev Mol Cell Biol 4:397-407.

Stennicke HR and Salvesen GS (1997) Biochemical characteristics of caspases-3, -6, -7, and -8. J Biol Chem 272:25719-25723.

Suzuki Y, Masini E, Mazzocca C, Cuzzocrea S, Ciampa A, Suzuki H, and Bani D (2004) Inhibition of poly(ADP-ribose) polymerase prevents allergen-induced asthma-like reaction in sensitized guinea pigs. J Pharmacol Exp Ther 311:12411248 .

Won JS, Im YB, Khan M, Singh AK, and Singh I (2004) The role of neutral sphingomyelinase produced ceramide in lipopolysaccharide-mediated expression of inducible nitric oxide synthase. J Neurochem 88:583-593.

Yamakura F, Taka H, Fujimura T, and Murayama K (1998) Inactivation of human manganese-superoxide dismutase by peroxynitrite is caused by exclusive nitration of tyrosine 34 to 3-nitrotyrosine. J Biol Chem 273:14085-14089.

Zhang G, Contos JJ, Weiner JA, Fukushima N, and Chun J (1999) Comparative analysis of three murine G-protein coupled receptors activated by sphingosine-1 phosphate. Gene 227:89-99.

Zhang YH, Vasko MR, and Nicol GD (2002) Ceramide, a putative second messenger for nerve growth factor, modulates the TTX-resistant $\mathrm{Na}^{+}$current and delayed rectifier $\mathrm{K}^{+}$current in rat sensory neurons. J Physiol 544:385-402.

Address correspondence to: Prof. Emanuela Masini, Dept. Preclinical and Clinical Pharmacology, University of Florence. Viale G. Pieraccini 6, I-50139 Florence, Italy. E-mail: emanuela.masini@unifi.it 